\title{
IDŐJÁRÁS
}

Quarterly Journal of the Hungarian Meteorological Service

Vol. 123, No. 4, October-December, 2019, pp. 435-453

\section{Analyzing the droughts in Iran and its eastern neighboring countries using copula functions}

\author{
Yousef Ramezani ${ }^{*}$, Mohammad Nazeri Tahroudi ${ }^{1}$, and Farshad Ahmadi ${ }^{2}$ \\ ${ }^{1}$ Department of Water Engineering, University of Birjand \\ Birjand, Iran \\ 2 Department of Hydrology and Water Resources Engineering, \\ Shahid Chamran University of Ahvaz \\ Ahvaz, Iran \\ *Corresponding Author E-mail: y.ramezani@birjand.ac.ir
}

(Manuscript received in final form November 28, 2018)

\begin{abstract}
As a long-term water deficit condition, drought is a challenging issue in the management of water resources and has been known as a costly and less known natural disaster. Monitoring and predicting droughts, especially accurate determination of their beginning and duration are crucial in management of water resources and planning for mitigating the damaging effects of drought. In this study, the droughts in the southwestern region of Asia (Iran, Afghanistan, Pakistan, and Turkmenistan) were evaluated using the joint deficit index (JDI). Data of monthly and annual precipitation of 1392 downscaled rain gauge stations (by using the Bias Correction Spatial Disaggregation (BCSD method) within the statistical period of 1971-2014 were employed to calculate JDI. The results indicated that in recent years, the number of dry months in the studied region (especially in humid regions of Iran) has significantly increased, such that across all regions in Iran, the percentage of dry months has reached over $50 \%$. The results also showed that in addition to scientific description of the general drought condition, JDI is also able to specify the time of beginning of droughts as well as long-term droughts, allowing investigation of the drought condition on a monthly scale. The results of investigating the trend of changes in the JDI values in the studied region revealed that the variations in these values have decreased on annual scale in the studied region. The extent of reduction in JDI and the increase in the number of dry months within the statistical period of 1971-2014 have been significant (at level of 5\%) in Iran, suggesting increased drought in Iran, especially during winter. The values of monthly and annual precipitation in the studied region have been descending, where among the studied countries, Iran has experienced the maximum extent of reduction in precipitation.
\end{abstract}

Key-words: copula functions, distribution function, drought, joint deficit index, empirical copula 


\section{Introduction}

Iran is located in one of the dry regions of the earth, and is affected by the deserts of the Middle Asia as well as dry and hot deserts of Saudi Arabia and Africa. Iran is considered one of the driest regions on the earth with the least rainfall. Climate change and global warming have intensified the droughts and their durations, causing distribution of precipitations to become non-uniform affecting water resources. Considering the importance of drought, extensive research has been conducted to study it. Every research has considered special aspects of drought. In the studies carried out across different regions of the world, various methods have been used to study drought, and in turn different results have been obtained. One of the most practical indices of drought is the standardized precipitation index (SPI), first introduced by McKee et al. (1993). SPI for any region is calculated based on the long-term precipitation statistics at intended scales. Although SPI has been widely accepted as a common general tool for evaluation of droughts, it has some limitations as well (Mishra and Singh, 2011). One of the limitations is that no standard duration has been introduced for SPI index sometimes presenting contradictory results under different timescales. Accordingly, for general evaluation of the droughts in a region, multiple SPIs should be investigated at the same time with different timescales (e.g., 1, 3, 6, 9, 12, 24, and 48 months) (Kao and Govindaraju, 2008). In order to eliminate the limitations in SPI, Kao and Govindaraju (2008) proposed a modified SPI. Unlike the conventional SPI which considers the general average (from beginning of the statistical period until its end) to separate wet and dry periods, in the modified SPI, the threshold limit is based on monthly average. It should be noted that although the modified SPI includes better statistical concepts, to obtain reliable marginal distributions, it needs longer recorded statistics. Further, in calculating modified SPI, as with conventional SPI, selecting different timescales (e.g., 1, 3, .. 24 months) results in variable results. To resolve this problem, Kao and Govindaraju (2008) combined the modified SPIs related to each month with different timescales using copula functions and developed a joint index. This index, which is called joint deficit index (JDI) is a multidimensional index for water deficit based on probability principles (Mirabbasi et al., 2012).

Copula functions were presented by Sklar (1959) to develop multivariate distributions. These functions were first employed in hydrology studies by De Michele and Salvadori (2003) to develop a bivariate model explaining the intensity and duration of rainfall. After that, the concept of copula functions was rapidly utilized across the various areas of hydrology including drought. Drought analysis using copula functions is a new field, which started in 2006 (Shiau, 2006). Considering application of copula in drought analysis, the following studies can be mentioned:

Wang et al. (2016) used JDI and monthly precipitation data within the statistical period of 1985-2011 to analyze drought in the Luanhe River basin. The 
results of this evaluation indicated that the drought frequency generally increases from northwest to southeast, and the drought in winter and summer is more intense. Nadi et al. (2017) used JDI to investigate the droughts in the Javanrood region in Kermanshah province located in the west of Iran. Their results suggested the existence of moderate and severe drought periods with a duration of 3 to 4 years in the region.

Based on the review of literature, it can be inferred that across the studies conducted on drought, precipitation data recorded in synoptic stations have been used. On the other hand, the coverage of downscaled data across each basin is wider as compared with synoptic stations. Therefore, usage of downscaled data better represents the changes in precipitation. Based on the reviewed points and considering climate change worldwide, it seems that examining droughts in Iran as well as its neighboring countries concurrently is essential. Iran is a broad country with different climates, in which precipitation distribution differs from region to region. Furthermore, since it is affected by the incoming air masses from the neighboring countries, the precipitation across the different regions of Iran is highly influenced by the situation of the neighboring countries. The aim of this study is to investigate meteorological drought conditions (using JDI) and the trend of its changes (using the modified Mann-Kendall test) in Iran and its eastern neighboring countries on a monthly scale within the statistical period of 19712014.

\section{Materials and methods}

\subsection{The studied region}

In this study, the monthly data and the sum of annual precipitation of 1392 downscaled rain gauge stations in Iran and its three neighboring countries (Afghanistan, Pakistan, and Turkmenistan) within the statistical period of 19712014 were used for investigating the drought in the regions of interest. The selected regions are located in warm and dry climates of Southwestern Asia. This region has very hot and dry summers and relatively short winters. The northern areas of this region are covered by mountain ranges, encompassing extensive areas of Turkey, Iran, and Afghanistan. In the eastern part of these protrusions, some flatlands can be seen, which have been created with the deposits of Tigris and Euphrates and have a fertile soil. The studied region and the effective air masses upon Iran in the summer and winter seasons are demonstrated in Figs. 1 and 2 , respectively. 


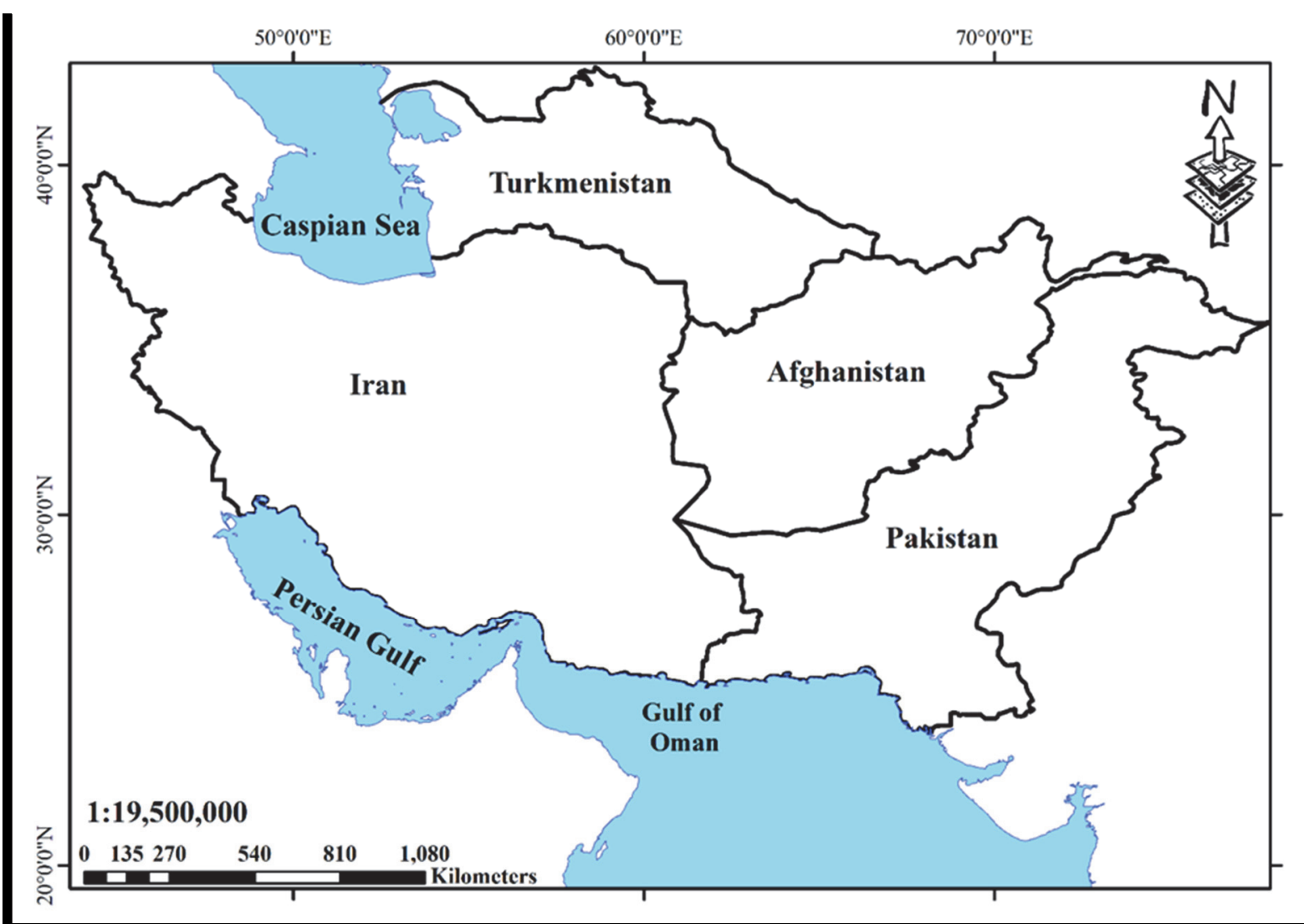

Fig. 1. The location of Iran and its eastern neighbors

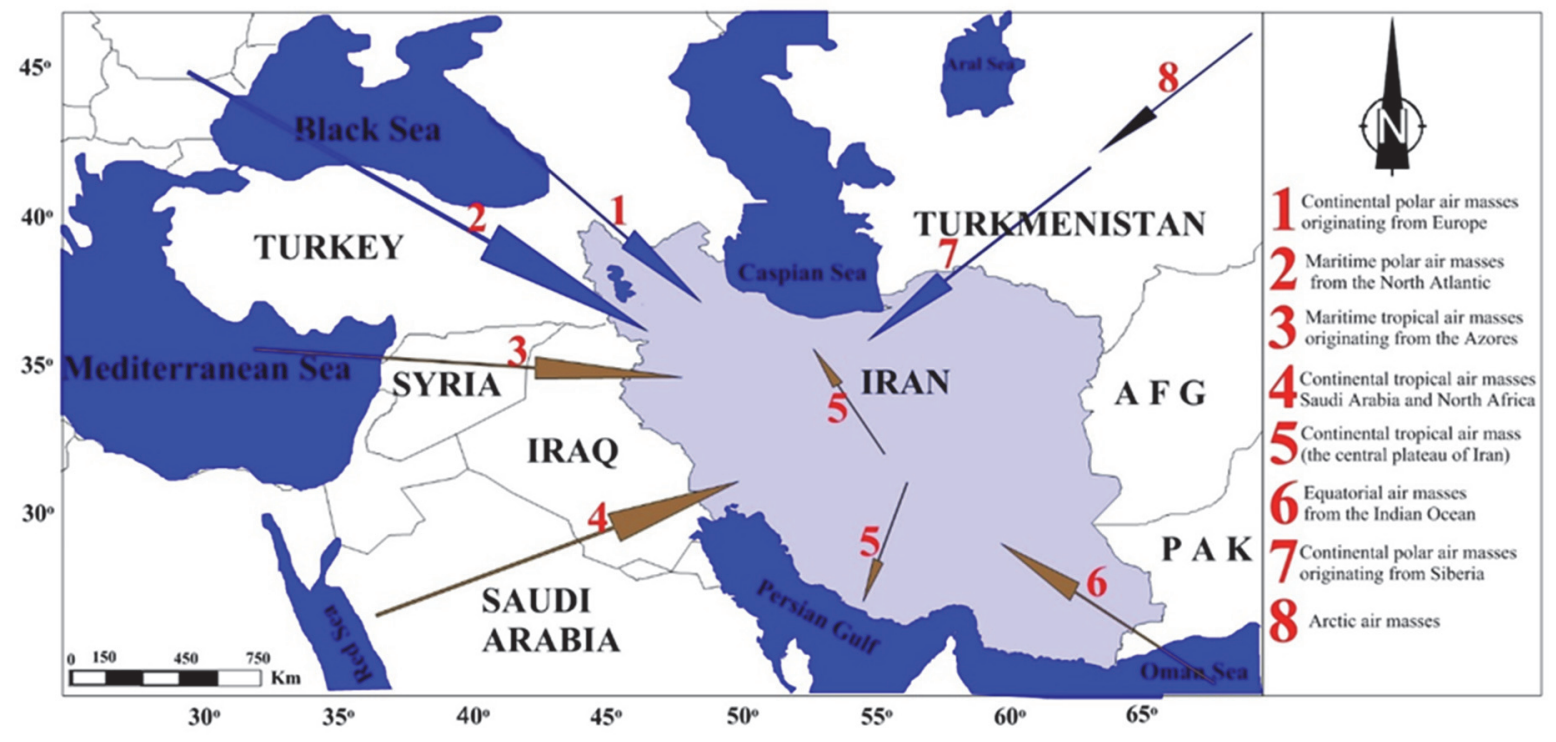

Fig. 2. Effective air masses upon Iran in the summer and winter seasons (Khalili et al., 2016) 


\subsection{Bias correction and spatial disaggregation (BCSD)}

This method was first utilized by Wood et al. (2002) for long-term predictions in the eastern part of the United States (Wood et al., 2002). It has also been used in recent years in the majority of monthly climatic studies. This method is so important that it has been used in the output of the fourth and fifth reports by the Intergovernmental Panel on Climate Change (IPCC) alongside other methods (Payne et al. 2004). The three major steps this method uses for exponential downscaling of the general circulation models outputs are as follows (Ahmed, 2011).

1. Correcting the statistical deviation of the general circulation models outputs on a monthly scale: in this step, two correction factors are generated for temperature and precipitation of the period related to the output of climatic models. Note that this correction factor is calculated on the network points related to the output of climatic models. Further, these factors are calculated in line with the observed and historical data.

$$
\left\{\begin{array}{l}
F_{t}=G C M_{t}-O B S_{t} \\
F_{p}=\frac{G C M_{p}}{O B S_{p}}
\end{array}\right.
$$

In this relation, $G C M_{t}$ and $G C M_{p}$ are the monthly temperature and precipitation of the general circulation models outputs, $O B S_{t}$ and $O B S_{P}$ represent the monthly observed temperature and precipitation at the station of interest. Eventually, $F_{p}$ and $F_{t}$ denote the correction factor for precipitation and temperature of the network points of general circulation models outputs. Generally, the time period of observed data and general circulation models outputs (historical) is considered the basic period in the fifth report by the Intergovernmental Panel on Climate Change within 1990-2006. Furthermore, the accuracy of the network points in most models has been stated as $2 * 2$.

2. After calculating the correction factors for the network points of the climatic models using interpolation instruments, these factors are estimated for higher accuracies of $1 * 1,0.5 * 0.5,0.25 * 0.25$, and $0.125 * 0.125$.

3. The correction factors obtained for higher accuracies are applied to the observed values according to Eq.(2), so that the general circulation models outputs would be estimated for the accuracy of interest. After obtaining the output values of the general circulation models for the new network points, the data around its surrounding points should be extracted considering the position of the observed station. 


$$
\left\{\begin{array}{l}
G C M_{t}=F_{t}+O B S_{t} \\
G C M_{p}=F_{p} \times O B S_{p}
\end{array}\right.
$$

Eventually and by accepting the assumption that the standard deviation of the basic and future periods of the general circulation models outputs is the same, the changes in the climatic components are determined for the future years.

\subsection{Copula functions and Sklar theory}

Copulas offer a flexible method for developing joint statistical distributions with different marginal distribution functions. Indeed, the copula is a function which links univariate marginal distribution functions for formation of a bi- or multivariate distribution function. The copulas are multivariate distribution functions whose one-dimensional margins are uniform within $(0,1)$. The introduction and presentation of copula functions have been attributed to Sklar, who described a theory suggesting how univariate distribution functions can be combined as multivariate distributions (Sklar, 1959).

Sklar indicated that for continuous $d$-dimensional random variables $\left\{X_{1}, \ldots, X_{d}\right\}$ with marginal cumulative distribution functions (CDFs, $) u_{j}=F_{X_{j}}\left(x_{j}\right)$ where $j=1, \ldots, d$, there is a unique d-dimensional copula, $C_{U_{1}, \ldots, U_{d}}$, where:

$$
C_{U_{1}, \ldots, U_{d}}\left(u_{1}, \ldots, u_{d}\right)=H_{X_{1}, \ldots, X_{d}}\left(x_{1}, \ldots, x_{d}\right) .
$$

$u_{j}$ is the $j$ th margin and $H_{X_{1}, \ldots, X_{d}}$ is the joint CDF of $\left\{X_{1}, \ldots, X_{d}\right\}$. Since for the continuous random variables of a $\mathrm{CDF}$ function the margins are non-descending from 0 to $1, C_{U_{1}, \ldots, U_{d}}$ function can be considered as a conversion of $\mathrm{H}_{\mathrm{X}_{1}, \ldots, \mathrm{X}_{d}}$ from $[-\infty, \infty]^{\mathrm{d}}$ to $[0,1]^{\mathrm{d}}$. The results of this conversion is that the marginal distributions detach off $H_{X_{1}, \ldots, X_{d}}$, and thus, $C_{U_{1}, \ldots, U_{d}}$ become related only to the relationship between the variables, offering a complete description of the general dependence structure (Nelson, 2007). Although the Sklar theory had been proposed for general dimensions $(d \geq 2)$, the complexity of the copulas grows rapidly with the increase in the number of variables. Therefore, most researchers use empirical copulas (especially for dimensions higher than 2) in a multivariate analysis. The concept of empirical copulas is indeed similar to the concept of the formula of plotting positions which are used in univariate statistical analysis (e.g., Weibull formula). These copulas are integral randomized cumulative probability metrics (Nelson, 2007). For a sample with the size of $n$, the $d$-dimensional empirical copula $C_{n}$ is as follows: 


$$
C_{n}\left(\frac{k_{1}}{n}, \frac{k_{2}}{n}, \ldots, \frac{k_{3}}{n}\right)=\frac{a}{n},
$$

where $a$ is equal to the number of observations $\left(x_{1}, \ldots, x_{d}\right)$ satisfying the condition of $x_{1} \leq x_{1\left(k_{1}\right)}, \ldots, x_{d} \leq x_{d\left(k_{d}\right)}$, in which $x_{1\left(k_{1}\right)}, \ldots, x_{d}$ with $1 \leq k_{1}, \ldots, k_{d} \leq n$ are the sequential statistics of the sample. In a similar method, the empirical distribution function

$\left(K_{C_{n}}\right)$ can be described as follows (Genest and Rivest, 1993):

$$
K_{C_{n}}\left(\frac{1}{n}\right)=\frac{b}{n}
$$

where $b$ is the number of samples $\left(x_{1}, \ldots, x_{d}\right)$ with $C_{n}\left(k_{1} / n, \ldots, k_{d} / n\right) \leq 1 / n$. Eq. (5) can also be stated as follows:

$$
K_{C_{n}}(t)=\frac{1}{n} \sum_{i=1}^{n} I\left(e_{j n} \leq t\right)
$$

where $e_{j n}$ is defined as follows:

$$
e_{j n}=\frac{1}{n-1} \sum_{i=1}^{n} I\left(x_{1(k)} \leq x_{1(j)}, \ldots, x_{d(k)} \leq x_{d(j)}\right)
$$

In which, $n$ is the sample size and $I(A)$ is the indicator variable of the logical statement $A$. If $A$ is true, then the value is 1 , while if it is wrong, the value becomes zero. $R_{i l}, \ldots, R_{i d}$ are the rank of the $i$ th observed data $\left(u_{1}, \ldots, u_{d}\right) . u_{w}$ represents the values of the cumulative distribution function related to the data. The empirical copulas $\mathrm{C}_{\mathrm{n}}$ and empirical distribution function $K_{C_{n}}$ are mostly used for model validation, and are considered as the observed dependence structure (real). When a sufficiently large sample is available, empirical copulas can be used for developing nonparametric integrated empirical distributions, which are more efficient computationally.

The meaning of the model is a theoretical copula function. In order to validate the copula function for forming the bivariate distribution, after fitting the suitable marginal distribution on every variables and estimating the distribution parameters, seven copula functions used to link the marginal functions. Finally, the best fitted copula function was selected by comparing the CDF values of every copula function with the corresponding values obtained from the empirical copula. For selecting the best copula function, the Nash-Sutcliffe (NS), Akaike information criterion (AIC), Cramér-von Mises (Sn), Root Mean Square Error (RMSE), Bias and Mean Absolute Error (MAE) criteria were used. 


\subsection{Joint deficit index (JDI)}

To specify the general condition of drought, the modified standardized precipitation index, $S P I^{m o d}$ values with different timescales were investigated. One of the comprehensive statistical processes for developing joint distribution of multiple $S P I^{\text {mod }}$ is using copulas. Kao and Govindaraju (2008) defined JDI using copula distribution functions to present a scientific description (based on probability) of the general condition of drought. To develop JDI, Gaussian and empirical copulas can be used to develop the dependence structure of the set. Nevertheless, given the mathematical complexity of 12-dimensional Gaussian copulas, Kao and Govindaraju (2008) used empirical copula for this purpose. Since the length of the data used in this study is relatively long (481 point data which are a result of 41 years in 12 months, though for the first 11 months, $u_{12}$ cannot be calculated), empirical copulas are reliable. Selection of $\left\{u_{1}, u_{2} \ldots, u_{12}\right\}$ in formation of high dimensional copulas increases the dependence model complexity.

Nevertheless, as the duration of the droughts shows extensive temporal changes by only considering different durations (from one to 12 months), droughts can be described well. The reason is that the annual cycle naturally considers the seasonal effects. In addition, this structure allows for one-month evaluation for the future conditions. Kao and Govindaraju (2008) did not consider margins longer than $12(j>12)$, since they observed that the samples utilized for $j>12$ begin to overlap, and even after using modified SPI process, they cause bias in the results. Therefore, in this study, to develop $J D I$, only 12 of the modified $S P I$ s were considered.

One copula is indeed the cumulative probability $P\left[U_{1} \leq u_{1}, \ldots U_{12} \leq u_{12}\right]=t$ of the sample margins $\left\{u_{1}, u_{2} \ldots, u_{12}\right\}$. As each margin shows the wet deficit conditions for each specific time period, the joint deficit conditions are characterized by $t$. Clearly, a smaller cumulative probability $t$ denotes drier conditions (dryness across different timescales), while larger $t$ values suggest more wet conditions. Assuming that $t$ reflects the intensity of joint drought, the probability of incidence of events with copula values smaller than or equal to $t$ (i.e,. events drier than a certain threshold limit) will be very useful.

For this purpose, the $K_{c}$ copula distribution function is defined, as the copula distribution function is the same as the cumulative probability $K_{C}(t)=P\left[C_{U_{1}, U_{2}, \ldots, U_{12}}\left(u_{1}, u_{1}, \ldots, u_{12}\right) \leq t\right]$. The special advantage of $K_{c}$ utilization is that it allows for calculating the probability criterion of the joint deficit conditions, which can be interpreted as a joint drought index.

Indeed, $K_{c}$ is the same as the $C_{U_{1}, U_{2}, \ldots, U_{l 2}}$ joint CDF. Thus, JDI was defined similarly to SPI (Kao and Govindaraju, 2008).

$$
J D I=\phi^{-1} K_{C} .
$$


As with $S P I$, positive $J D I$ value $\left(K_{c}>0.5\right)$ suggests overall wet conditions; a negative $J D I\left(K_{c}<0.5\right)$ shows overall dry conditions, and $J D I=0\left(K_{c}=0.5\right)$ shows normal conditions. Since $J D I$ is on an inverse normal scale (as with $S P I$ ), classification of droughts based on SPI can also be used for JDI (Table 1). The most important property of $J D I$ is to evaluate the general deficit conditions based on the dependence structure of the deficit indices with different time periods.

Table 1. Classification scale for the SPI values and corresponding event probability limits (McKee et al., 1993; Bazrafshan et al., 2015). It can be used for the modified SPI, MSPI, and JDI

\begin{tabular}{lcc}
\hline \hline \multicolumn{1}{c}{$\boldsymbol{S P I}$ classes } & SPI intervals & Probability limit \\
\hline \hline Extremely wet & $S P I \geq 2$ & $\geq 97 \%$ \\
Severely wet & $2>S P I \geq 1.5$ & $93.3-97.7 \%$ \\
Moderately wet & $1.5>S P I \geq 1$ & $84.1-93.3 \%$ \\
Normal & $1>S P I>-1$ & $15.9-84.1 \%$ \\
Moderately dry & $-1 \geq S P I>-1.5$ & $6.7-15.9 \%$ \\
Severely dry & $-1.5 \geq S P I>-2$ & $2.3-6.7 \%$ \\
Extremely dry & $S P I \leq-2$ & $\leq 2.3 \%$ \\
\hline
\end{tabular}

The trend of changes in $J D I$ values was also examined using the modified Mann-Kendall test (Rezaie et al. 2014; Khalili et al. 2016; Ahmadi et al. 2018; Zamani et al. 2018). The main assumption of the Mann-Kendall test is that the sample data has no significant autocorrelation. However, some hydrological series might have a significant autocorrelation coefficient (Khalili et al., 2016). When a series has a positive autocorrelation coefficient, there is an increased chance for the Mann-Kendall test to reveal existence of a trend in this series. In this case, the null hypothesis is that the lack of trend is rejected, yet this hypothesis should not actually be rejected (Khalili et al. 2016). In this method, the effect of all significant autocorrelation coefficients is removed from the time series and is applied to series whose autocorrelation coefficients are significant in one or more cases. Here, the modified variance $V(S) *$ is calculated as follows:

$$
\begin{gathered}
V(S)^{*}=V(S) \frac{n}{n^{*}}, \\
\frac{n}{n^{*}}=1+\frac{2}{n(n-1)(n-2)} \cdot \sum_{i=1}^{n-1}(n-i)(n-i-1)(n-i-2) r_{i},
\end{gathered}
$$




$$
\begin{gathered}
\operatorname{Var}(S)=\frac{n-(n-1)(2 n+5)-C}{18}, \\
Z= \begin{cases}\frac{S-1}{\sqrt{\operatorname{Var}(s)}} & \text { if } S>0 \\
0 & \text { if } S=0, \\
\frac{S+1}{\sqrt{\operatorname{Var}(s)}} & \text { if } S<0\end{cases}
\end{gathered}
$$

where $r_{i}$ is the $i$ delayed autocorrelation coefficient and $V(S)$ is estimated by Eq. (11). To calculate the $Z$ statistic in the modified Mann-Kendall test in Eq. (12), $V(S)$ is substituted by $V(S)^{*}$. The value of $Z$ statistic obtained from Eq. (12) is compared with normal standard $Z$ at $\alpha$ significant level.

Finally, the flowchart of proposed methodology is shown in Fig. 3.
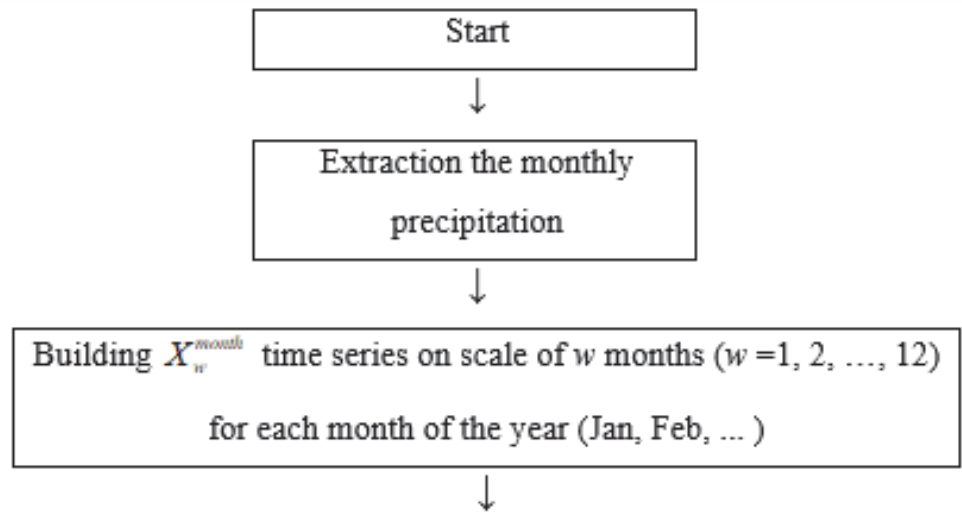

Fitting the gamma statistical distribution on each $X_{w}^{\text {mons }}$ series and

the estimation of $\alpha$ and $\beta$ parameters for each month of the year

$\downarrow$

Calculation of cumulative probabilistic of gamma distribution for each month $\left(u_{w}^{\text {moust }}=F_{x_{v}^{\operatorname{minh}}}\right)$

$\downarrow$

Calculation the values of the experimental joint function

$C_{U_{1}, U_{12}}\left(u_{1}^{\text {momol }}, \ldots, u_{12}^{\text {monst }}\right)$ and its corresponding values of $K_{C}$

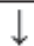

Converting the $K_{C}$ values to normal and standard values and calculating the $J D I=\phi^{-1}\left(K_{C}\right)$

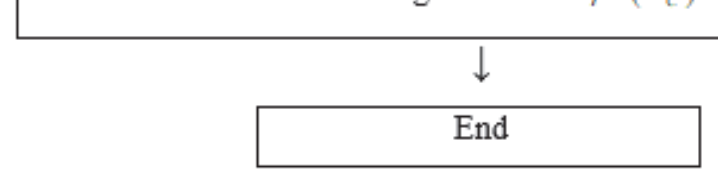

Fig. 3. Flowchart of the proposed methodology. 


\section{Results and discussion}

In this study, the monthly data of annual precipitation of 1392 downscaled rain gauge stations in Iran and its three eastern neighboring countries were used to investigate the monthly droughts using copula functions. In this study, the monthly precipitation data of Iran, Afghanistan, Pakistan, and Turkmenistan were used. The results of calculating $J D I$ values on monthly timescale in 2014 have been presented as a sample in the form of box plots (Figs. 4-7).

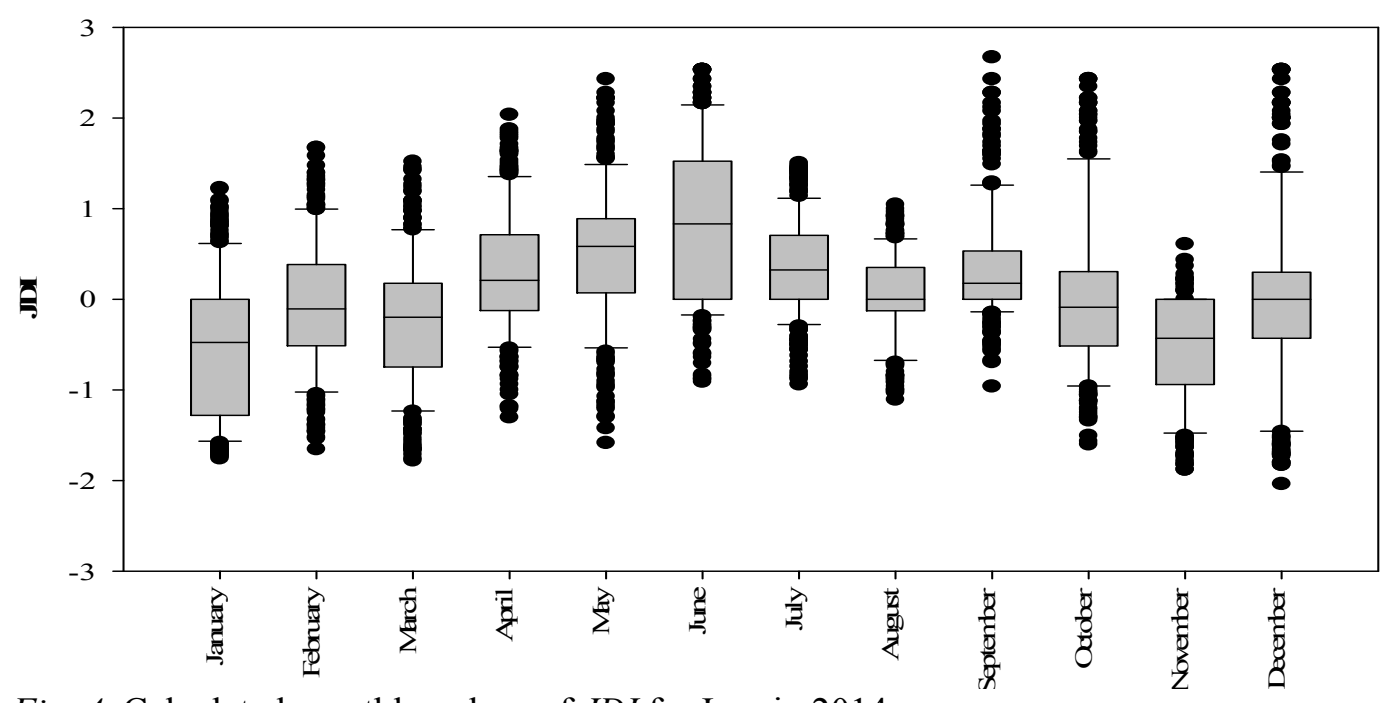

Fig. 4. Calculated monthly values of JDI for Iran in 2014.

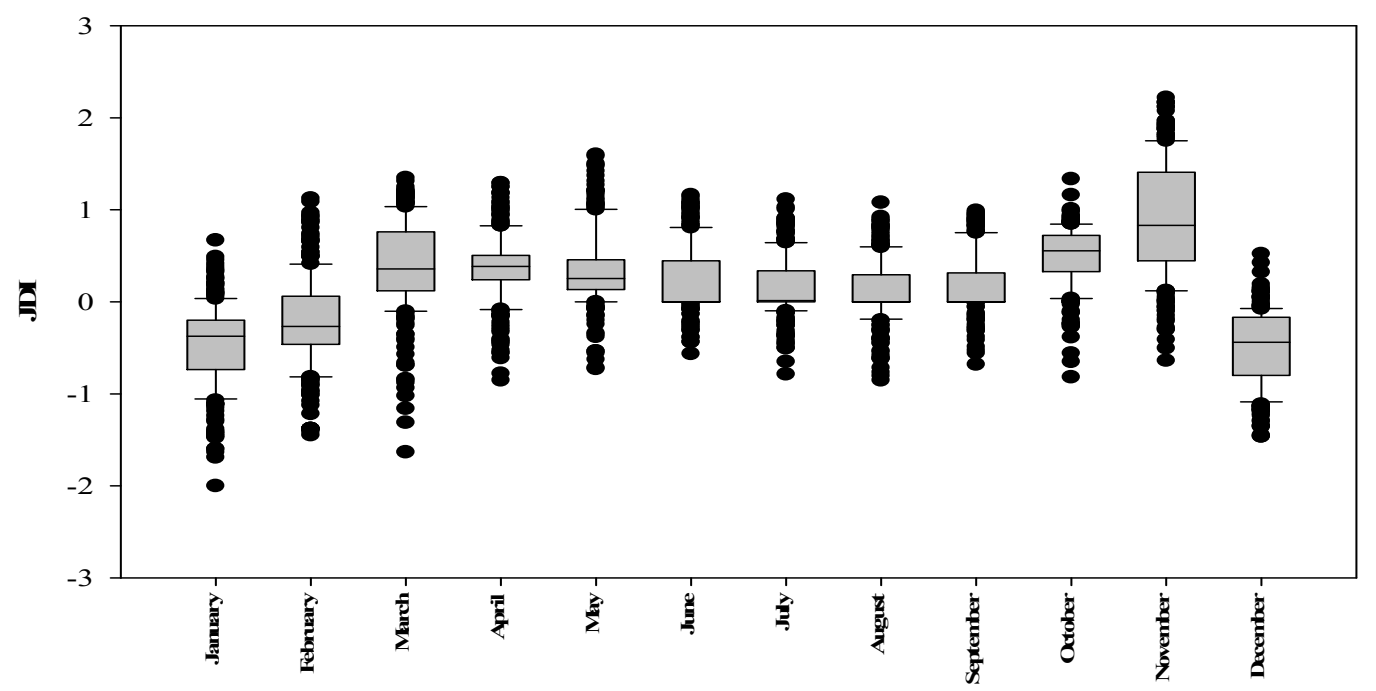

Fig. 5. Calculated monthly values of JDI for Afghanistan in 2014. 


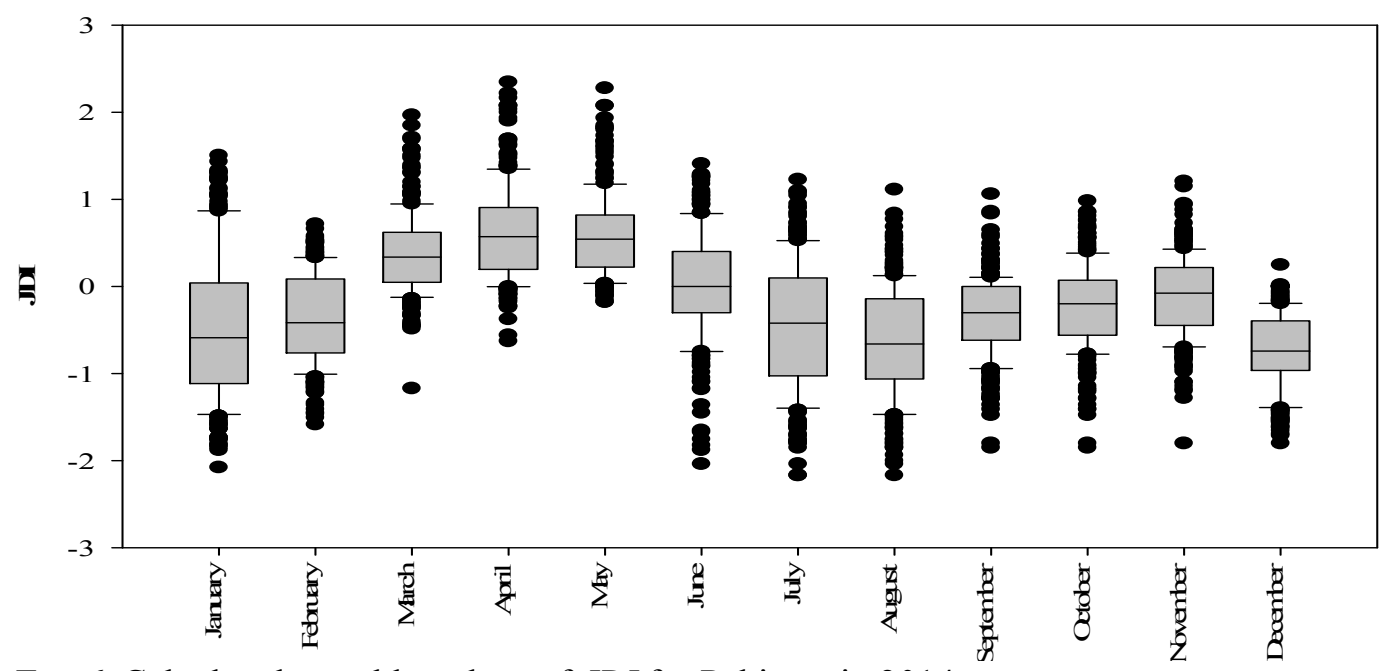

Fig. 6. Calculated monthly values of $J D I$ for Pakistan in 2014.

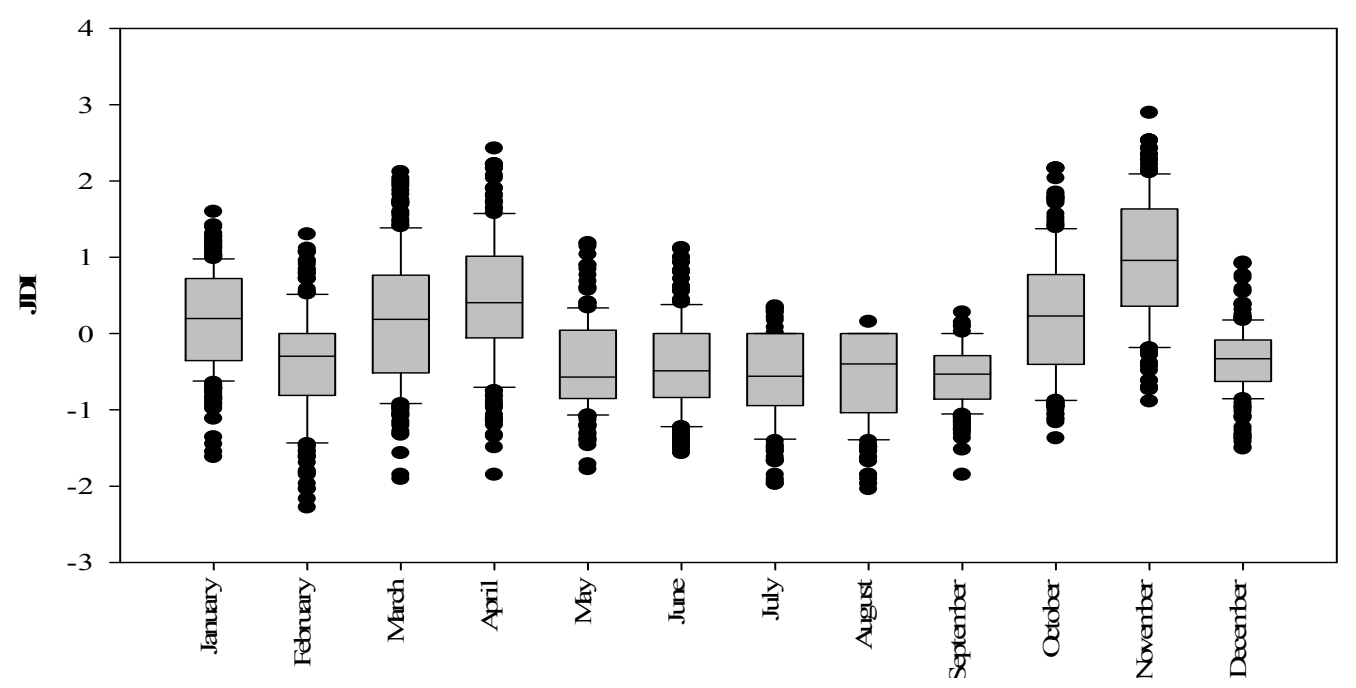

Fig. 7. Calculated monthly values of JDI for Turkmenistan in 2014.

\subsection{The results of investigating JDI in Iran}

The results of investigating $J D I$ in Iran indicate that at the beginning of the statistical period, the major changes in $J D I$ values in January, February, June, and October are negative and show normal conditions (0 to -1). In April, May, July, August, November, and December, better conditions governed the region. However, this superiority is also limited to normal conditions. The changes in monthly $J D I$ values in 2014, as presented according to Fig. 4, suggest normal conditions in April, May, June, July, August, September, and October, as the major changes in $J D I$ values are close to zero or more. 


\subsection{The results of investigating JDI in Afghanistan}

The results of investigating $J D I$ in Afghanistan indicate that at the beginning of the statistical period, the changes in $J D I$ values varied considerably across the different months. Most of the changes in this parameter have occurred in January between -1 and -0.8 , suggesting normal conditions in the region. The major changes in $J D I$ values during 1971 were less than zero in all months, suggesting normal conditions across the months of the year at the beginning of the statistical period. The major changes in JDI values in February, March, and May are somehow similar to those of January. August, July, and June in 1971, which had the greatest range of changes in $J D I$ values. In this regard, in Jul, these changes reach below 1. December, November, and September have better conditions as compared with other months, when $J D I$ values are closer to zero. Several cases showed numbers above zero across different stations and in different months. The major changes in $J D I$ values in this country in 1971 suggest normal conditions in the region.

At the end of the studied statistical period, the results of investigating $J D I$ values suggest amelioration of drought conditions in March-November ( -0.8 to 1.35). Except for Jan and December, when moderately dry conditions were experienced, other months have close to normal conditions. Based on Fig. 5, it can be concluded that the $J D I$ values calculated in Afghanistan within the studied statistical period suggest amelioration of climate conditions in this country.

\subsection{The results of investigating JDI in Pakistan}

The results of investigating $J D I$ in Pakistan indicate that the beginning of the statistical period shows moderately dry condition. The major changes in JDI values in February, March, April, and May lie in -1.5- 0, suggesting moderately dry and normal conditions. According to classification of $J D I$, almost in all months, moderately dry conditions govern the region. However, these changes in 2014 (Fig. 6) in March, April, and May show normal conditions. Other months have worse conditions as compared with the beginning of the statistical period, representing moderately dry and almost normal conditions.

\subsection{The results of investigating JDI in Turkmenistan}

The results of investigating $J D I$ in Turkmenistan suggest normal conditions ( -1 to 0 ) in the region at the beginning of the statistical period. The changes in JDI values are better in Apr as compared with other months. However, this superiority is also limited to normal conditions. As with other countries, the changes in JDI values in 2014 have progressed towards normal and sometimes moderately dry conditions (Fig. 7). Distribution of $J D I$ values across the studied region in 2014 is presented in Fig. 8 . 


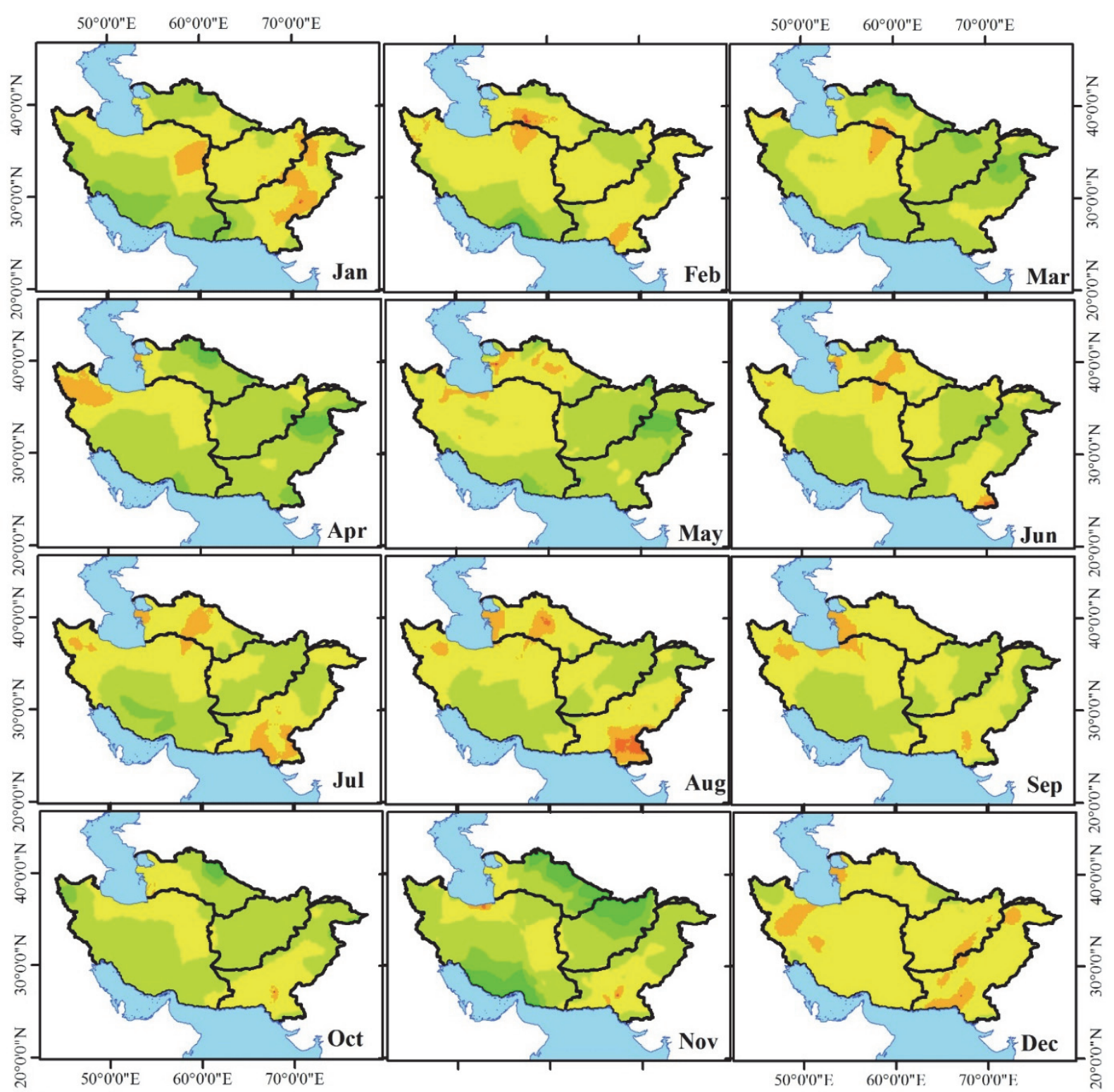

Legend

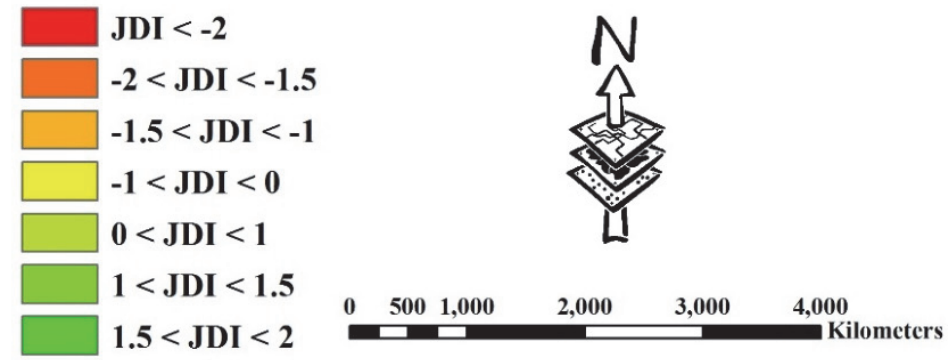

Fig. 8. Zoning of the $J D I$ values across the studied region in 2014.

In 2014 and in January, most areas of Iran had a suitable status in terms of $J D I$. Also other months including May, April, March, June, October, and November experienced normal and moderately wet conditions in most areas of the studied region. However, in this year (2014) in Dec, almost all areas of the 
studied region experienced moderately dry conditions. Generally, the results of zoning $J D I$ values across the studied region indicated that in recent years in winter, precipitation deficit has prevailed the studied region.

Considering the dramatic changes in JDI parameter during the studied statistical period among the selected months, and to more accurately investigate the changes in these values $(J D I)$, the trend of its monthly and annual changes should be examined within a 45-year-long statistical period (1971-2014). Based on the mentioned points, the trend of changes in $J D I$ values within the 45 -year statistical period was examined by the modified Mann-Kendall test. The results obtained from investigating the trend of changes in $J D I$ values on an annual scale are presented in Fig. 9.

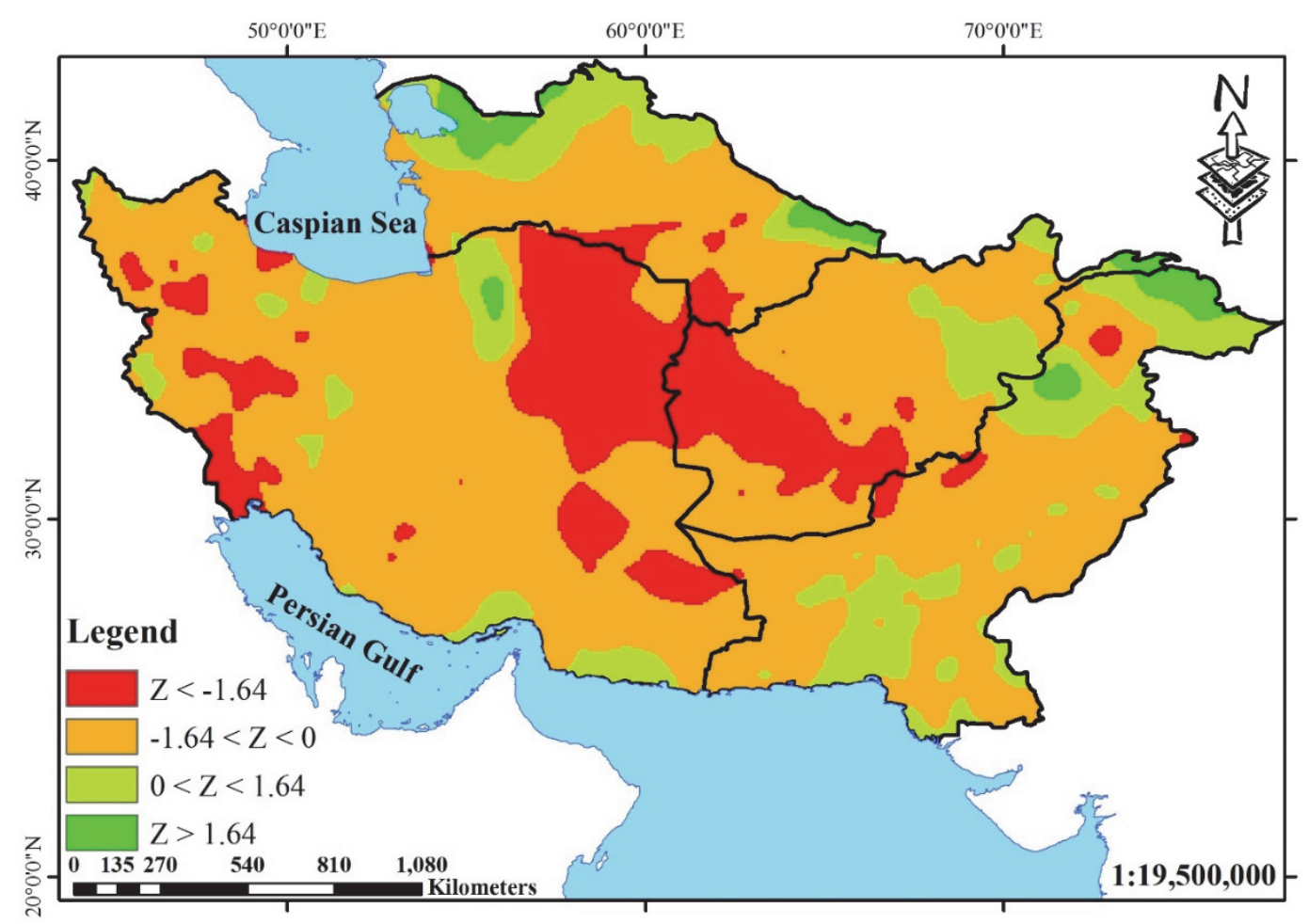

Fig. 9. Zoning of the trend of changes in JDI values on annual scale.

The results of investigating the trend of changes in droughts in Jan suggest increased droughts with a significant reduction in $J D I$ values in the eastern and northeastern areas of Iran as well as at the Iran and Afghanistan borderline. In this month, the descending trend of $J D I$ values can be observed across almost the entire studied region, which in turn shows increased droughts.

However, in February, the trend of long-term changes in monthly $J D I$ values in the eastern regions of the studied zone (the eastern regions of Afghanistan and 
Pakistan) as well as the northern borderline of Turkmenistan was ascending, suggesting diminished droughts in these regions. This situation of Iran became more critical in February in relation to January. The western and eastern regions of Iran have had a descending insignificant trend in $J D I$ values, suggesting increased droughts.

In March, as compared with January and February, the situation of Iran became more critical. Iran suffers from more serious drought condition compared to its three eastern neighbors. In this month (March), droughts have grown significantly in Iran. However, the eastern areas of Pakistan and Afghanistan have suitable conditions in terms of precipitation. The northern regions of Turkmenistan in this month (March) have also better conditions compared to Iran.

The results of investigating the trend of changes in $J D I$ values in the studied region indicated that in April, the trend of changes in JDI values in the northeastern, southern, and northwestern areas of Iran experienced a descending and significant trend, suggesting increased drought in these areas. In this month (Apr), the changes in $J D I$ values in the central and southeastern areas of Iran have been ascending, suggesting diminished level of drought and deficit of precipitation in this month within the statistical period of 1971-2014. In April, the changes in droughts have also been descending in the northern parts of Turkmenistan as well as eastern areas of Afghanistan and Pakistan.

In May, the intensity of droughts in the central areas of Iran has decreased. However, the descending trend of $J D I$ values still prevail the entire country. In this month (May), the changes of $J D I$ values are ascending in the eastern areas of Afghanistan and Pakistan. This trend has also changed in June in Iran. In this month, in the central and southeastern areas of Iran, the trend changes in JDI values has been increasing, suggesting diminished drought and increased precipitation fluctuations. The eastern neighbors of Iran have also had a suitable situation in terms of drought. The growing changes of $J D I$ values in Jul in Iran have reached the central areas of the country. The variations of $J D I$ values in Jul have been decreasing and significant in parts of eastern Iran and southeastern Pakistan. From among the studied countries, the situation in Afghanistan in July is better than in other countries.

In August, the changes in $J D I$ values in the studied area have been better, as compared with other months, where ascending changes are observed in JDI values in most areas, and these changes are also observed in September. In this month (Sep), the situation in the eastern neighbors of Iran is better than in all of the studied countries. These conditions of improved droughts in October are clear in the neighboring countries. However, in Iran in October, the predominant trend is also descending. In November, the ascending trend of $J D I$ values in the neighboring countries can be clearly observed. However, across Iran, these changes are diminishing in the northwestern, western, and northeastern areas of the country.

In December, which is one of the winter months in Iran, diminishing changes of $J D I$ values prevail the entire country. Apart from the eastern regions of 
Afghanistan and Pakistan, as well as the northern and southern areas of Turkmenistan, other areas have experienced descending JDI values. These diminishing changes in this month and in winter suggest lowered precipitation and increased droughts, which is very serious.

On annual scale, the results of investigating and zoning by the aid of the Mann-Kendall $\mathrm{Z}$ statistic across the studied region indicated that the trend of changes in $J D I$ values within the statistical period of 1971-2014 is descending and significant in the northwestern, western, southeastern, eastern, and northeastern areas of Iran, suggesting significant increase in droughts in these areas. On the annual scale, the western areas of Afghanistan and Pakistan as well as northern parts of Turkmenistan have experienced an ascending trend in JDI values, suggesting normal conditions in these areas. The predominant trend of JDI values in Iran is descending on the annual scale.

Monsoons during summer develop warm and humid tropical weather. This weather enters the southern areas of Iran in two ways: first through sea breeze which enters Iran from the Oman Sea and Persian Gulf up to a limited radius and altitude. Its area is very small and due to high pressure development of Azores High above the region, it does not have a significant effect on precipitation. The second way is the entrance of monsoon weather through low-pressure heat during summer in Pakistan and India. Nevertheless, the frequency and intensity of the summer monsoon rainfalls are low given the side of their entrance. The climatic effect of Saudi Arabia lands mostly emerges during summer. In the warm period of the year, due to establishment of Azores High over Iran, Iran's sky is devoid of cloud, thus causing the Earth's surface warming. The global warming develops a low-pressure center on the Persian Gulf. This low-pressure center pulls in the weather of Saudi Arabia Peninsula into Iran. Entrance of warm and dry weather of Saudi Arabia into Iran causes elevation of the temperature of the Khuzestan Plain cities, whereby dry and warm weather prevails this region. The increase in the droughts of the region suggests lowered level of precipitations, and the existence of a descending trend of precipitation across Iran has also been confirmed by various studies including Kousari et al. (2013) and Khalili et al. (2014).

\section{Conclusion}

Statistical analysis of the monthly and annual precipitation data of Iran and its neighboring countries is crucial in terms of precipitation deficit distribution climatically. Accordingly, investigating an index which can reveal this joint precipitation deficit is important. $J D I$ is an index for determining changes in precipitation in a certain region, and the results of its analysis can indicate drought in an environment. In this study, $J D I$ was used to analyze the drought and precipitation deficit on annual and monthly scales in Iran and its eastern neighboring countries including Afghanistan, Pakistan, and Turkmenistan within 
the statistical period of 1971-2014. In addition to examining JDI across the studied region, the trend of changes in precipitation as well as trend of variations in $J D I$ values was also investigated across the studied region. The results of investigating and zoning of $J D I$ values on annual and monthly scales in the studied region showed that from among the studied countries, the drought condition and precipitation deficit is worse in Iran, and the extent of droughts in Iran is more than that of its eastern neighboring countries. The extent of droughts has also increased in recent years (up to 2014), according to the values presented by JDI. The results of investigating the trend of changes of precipitations in the studied region suggested a significant decrease in the precipitation in Iran within 19712014 on monthly and annual scales. Meanwhile, the share of Iran in terms of precipitation reduction is larger as compared with its neighboring countries including Turkmenistan, Afghanistan, and Pakistan. The results of investigating the trend of changes in $J D I$ values across the studied region indicated that the variations of $J D I$ values on annual scale have been descending in the studied region. Based on the obtained results, it was found that the trend of changes in $J D I$ values in Iran (such as diminishing precipitations) has been more declining as compared with other countries, suggesting increased droughts in recent years. The results imply descending changes of $J D I$ values across the entire Iran. Generally, the results of zoning of $J D I$ values across the studied region indicated that in recent years in winter, precipitation deficit has prevailed the studied region.

Acknowledgements: The authors would like to thank the Climatic Research Unit of University of East Anglia (http://www.cru.uea.ac.uk/data) and the Iranian Meteorological Organization (IMO) for providing the meteorological data. Also, the authors are thankful to the University of Birjand, Birjand, Iran.

\section{References}

Ahmadi, F., Nazeri Tahroudi, M., Mirabbasi, R., Khalili, K. and Jhajharia, D., 2018: Spatiotemporal trend and abrupt change analysis of temperature in Iran. Meteorol. Appl. 25, 314-321. https://doi.org/10.1002/met.1694

Ahmed, K.F., 2011: Bias Correction and Downscaling of Climate Model Outputs Required for Impact Assessments of Climate Change in the US Northeast, Master's theses, University of Connecticut OpenCommons@UConn

Bazrafshan, J., Nadi, M. and Ghorbani, K., 2015: Comparison of empirical copula-based joint deficit index (JDI) and multivariate standardized precipitation index (MSPI) for drought monitoring in Iran. Water Resour. Manage. 29:2027-2044. https://doi.org/10.1007/s11269-015-0926-x

De Michele, C. and Salvadori, G., 2003: A generalized Pareto intensity-duration model of storm rainfall exploiting 2-copulas. J. Geophys. Res.: Atmospheres 108, D2. https://doi.org/10.1029/2002JD002534

Genest, C. and Rivest, L-P., 1993: Statistical inference procedures for bivariate Archimedean copulas. J. Amer. Statistic. Assoc. 88,1034-1043. https://doi.org/10.1080/01621459.1993.10476372

Kao, S.C. and Govindaraju, R.S., 2008: Trivariate statistical analysis of extreme rainfall events via the Plackett family of copulas. Water Resour. Res. 44(2). https://doi.org/10.1029/2007WR006261 
Khalili, K., Esfandiary, S., Khanmohammadi, N. and Nazeri Tahrudi, M., 2014: Half-century air temperature trends in Iran. J.Midd. East Appl. Sci. Technol. 8, 208-213.

Khalili, K., Tahoudi, M.N., Mirabbasi, R. and Ahmadi, F., 2016: Investigation of spatial and temporal variability of precipitation in Iran over the last half century. Stoch. Environ. Res. Risk Ass. 30, 1205-1221. https://doi.org/10.1007/s00477-015-1095-4

Kousari, M.R., Ahani, H. and Hendi-zadeh, R., 2013: Temporal and spatial trend detection of maximum air temperature in Iran during 1960-2005. Glob. Planet. Change 111, 97-110. https://doi.org/10.1016/j.gloplacha.2013.08.011

McKee, T.B., Doesken, N.J., and Kleist, J., 1993: The relationship of drought frequency and duration to time scales. In: Proceedings of the 8th Conference on Applied Climatology, 1993. vol 22. American Meteorological Society Boston, MA.179-183.

Mirabbasi, R., Fakheri-Fard, A., and Dinpashoh, Y., 2012: Bivariate drought frequency analysis using the copula method. Theor. Appl. Climatol. 108, 191-206. https://doi.org/10.1007/s00704-011-0524-7

Mishra, A.K. and Singh, V.P., 2011: Drought modeling-A review. J. Hydrol. 403,157-175. https://doi.org/10.1016/j.jhydrol.2011.03.049

Nadi, M., Bazrafshan, J., Pourtahmasi, K., and Bräuning, A., 2017: Tree-ring based reconstruction of the joint deficit index in Javan-Roud Region, Kermanshah (Iran). Int. J. Climatol. 37,420-429. https://doi.org/10.1002/joc.4715

Nelsen, RB., 2007: An introduction to copulas. Springer Science \& Business Media.

Payne, JT., Wood, AW., Hamlet, AF., Palmer, RN., and Lettenmaier, DP,. 2004. Mitigating the effects of climate change on the water resources of the Columbia River basin. Climatic change. 62,(1-3), 233-256.

Rezaie, H., Khalili, K., Khanmohammadi, N., and Nazeri Tahrudi, M., 2014. Surface air temperature trends during the last 20 years in Iran. J. Appl. Environ. Biol. Sci. 4(1s), 40-46.

Shiau, J., 2006: Fitting drought duration and severity with two-dimensional copulas. Water Resour. Manage. 20, 795-815. https://doi.org/10.1007/s11269-005-9008-9

Sklar, A., 1959: Distribution functions of $\mathrm{n}$ dimensions and margins. Publications of the Institute of Statistics of the University of Paris 8, 229-231.

Wang, Y., Li, J., Feng, $P$., and Hu, R., 2016: Analysis of drought characteristics over Luanhe River basin using the joint deficit index. J. Water Clim. Change 7, 340-352. https://doi.org/10.2166/wcc.2015.108

Wood, A.W, Maurer, E.P., Kumar, A., and Lettenmaier, D.P., 2002: Long-range experimental hydrologic forecasting for the eastern United States, J. Geophysical Research: Atmospheres. 107, D20: ACL-6. https://doi.org/10.1029/2001JD000659

Zamani, R., Mirabbasi, R., Nazeri, M., Meshram, S. G. and Ahmadi, F., 2018. Spatio-temporal analysis of daily, seasonal and annual precipitation concentration in Jharkhand State India. Stoch. Environ. Res. Risk Ass. 32, 1085-1097. https://doi.org/10.1007/s00477-017-1447-3 